\title{
Increased Cellular Levels of MicroRNA-9 and MicroRNA-221 Correlate with Cancer Stemness and Predict Poor Outcome in Human Breast Cancer
}

\author{
Chun-Wen Cheng ${ }^{a, b} \quad J y h-C h e r n g ~ Y u^{c} \quad$ Yi-Hsien Hsieh ${ }^{a} \quad$ Wen-Ling Liaod,e \\ Jia-Ching Shieh $^{f}$ Chung-Chin Yao ${ }^{g}$ Huei-Jane Lee $^{a}$ Po-Ming Chen ${ }^{a}$ \\ Pei-Ei Wu ${ }^{\text {h }}$ Chen-Yang Shen ${ }^{\text {hi }}$
}

Institute of Biochemistry, Microbiology and Immunology, Chung Shan Medical University, Taichung, ${ }^{b}$ Clinical Laboratory, Chung Shan Medical University Hospital, Taichung, 'Department of Surgery, TriService General Hospital, National Defense Medical Center, Taipei dGraduate Institute of Integrated Medicine, China Medical University, Taichung, ${ }^{e}$ Center for Personalized Medicine, China Medical University Hospital, Taichung, fDepartment of Biomedical Sciences, Chung Shan Medical University, Taichung, 9Department of Surgery, Chung Shan Medical University Hospital, Taichung, 'Institute of Biomedical Sciences, Academia Sinica, Taipei, 'College of Public Health, China Medical University, Taichung, Taiwan

\section{Key Words}

Breast cancer $・$ MiR-9 $\bullet$ MiR-221 • Prognosis $・$ Stemness

\begin{abstract}
Background /Aims: Recent studies of microRNA (miRNA) involvement in tumorigenesis have indicated the critical role of these non-coding small RNAs in malignant transformation, but the prognostic role, if any, of miRNAs in breast cancer remains undetermined. Therefore, we assessed the prognostic significance of microRNA-9 (miR-9) and miR-221 in breast cancer toward the goal of understanding the contribution(s) of these miRNAs to cancer cell stemness. Methods: The level of each of miR-9 and miR-221 in 206 paired laser capture microdissected tumor cells and non-tumor cells was determined by quantitative reverse transcription-PCR (qRT-PCR). The relationship between the miRNA signature and clinicopathological data and prognosis of breast cancer was assessed. Identification of a stem cell-enriched side population was achieved with fluorescence-activated cell sorting and a sphere-forming assay. Wound healing, Boyden chamber assays, and western blotting were used to study the contribution of each miRNA to tumor cell migration and invasion. Results: We found that induction of miR9 and miR-221 mimics conferred side-population cells to form spheroidal tumor colonies in suspension culture that maintained the mesenchymal stem-cell potential in non-invasive MCF7 breast cancer cells. In contrast, knockdown of both miR-9 and miR-221 in invasive MDA-


MB-231 breast cancer cells dramatically decreased the number of side-population colonies with stem cell-like potency, which reduced the capacity for tumor-cell renewal, invasion, and migration. Clinically, the mean proportion of miR-9- or miR-221-overexpressing cells was significantly greater in tumor cells compared with non-tumor cells $(P<0.05)$. Increased levels of miR-9 and miR-221 in breast tissue portended a significantly elevated risk of progression to malignancy with respect to larger tumor size, poor differentiation, late-stage evolution, lymph-node metastasis $(P<0.05)$, and lower overall survival $\left(P_{\text {trend }}=0.017\right.$; eight-year followup). Conclusion: Our findings provide strong evidence that miR-9 and miR-221 can enhance the generation of cancer stem cells to yield an invasive phenotype and that overexpression of these miRNAs predicts a poor outcome for breast cancer patients.

\section{Introduction}

Breast cancer is the second leading cause of cancer death among women worldwide, and the prevalence and mortality rates are high in Western countries. Nevertheless, previous work has helped to define the clinicopathologic features of breast cancer, such as histological grade, lymph-node involvement, and status of hormone receptors, which have improved prognostic evaluation and guided therapeutic approaches for the disease $[1,2]$. The malignant transformation of tumor cells occurs via a multistep process that involves the reprogramming of pluripotency, which is considered the most challenging issue facing therapeutic intervention [3]. Side-population (SP) cells constitute an enriched source of cancer-initiating cells with an increased capacity to efflux anti-cancer drugs via the transporter of the ATP-binding cassette (ABC) superfamily, such as the ABC subfamily G member 2 encoded by $A B C G 2$, the overexpression of which serves as a hallmark of cancer stem cells [4,5]. SP cells constitute a distinct subpopulation of cancer cells that are similar to normal adult stem cells that reside in regenerative tissues, and they share many stemness properties such as the capacity for self-renewal, regeneration, and re-differentiation [6]. The epithelial-to-mesenchymal transition (EMT), which commonly occurs during tumorigenesis, regulates SP cell behavior with respect to the potential to undergo hyperproliferation, local invasion, and distant metastasis and develop resistance to apoptotic stimuli within the renewable tumor clone [7-9]. Thus, a better understanding of the biomarkers that link the EMT with the generation of SP cells will allow prognoses to be more effective and inform treatment strategies for breast cancer.

MicroRNAs (miRNAs) are a class of short, non-coding RNAs (18-25 nucleotides) that bind the 3'-untranslated region of target mRNAs and thereby serve as post-transcriptional modulators of gene expression. There has been a growing attention to address the role of miRNAs as promoters or suppressors which regulate a vast range of physiological responses in tumor progression [10,11], especially, for their functions in regulating the cellular levels of tens to hundreds of mRNAs and can affect many biological pathways, including those involved in the reprogramming of pluripotent stem cells [12-14]. As such, we hypothesized that deregulation of miRNAs that are expressed specifically in stem cells that reside among SP cells could promote the EMT and thereby potentiate metastatic disease. Recent studies of microRNA-9 (miR-9) and micro RNA-221 (miR-221) suggest their involvement in oncogenesis and EMT activation as well as in the enhancement of the metastatic phenotypes observed in various types of human cancer $[15,16]$. However, it remains unknown whether the EMT can be reactivated by these two miRNAs in SP cells to acquire the mesenchymal phenotypes that are characteristic of breast cancer cells, and thus the clinical significance of miR-9/221 overexpression is unclear with respect to the outcomes of breast cancer patients. Therefore, we evaluated the fates of stem cell-like cells derived from breast tumors in which miR-9 and/or miR-221 had been up- or downregulated in vitro. We also report clinical information concerning the differential expression of miR-9 and miR-221 in tumor cells compared with non-tumor cells to inform the prognosis of patients in our breast cancer study cohort beyond the standard eight-year follow-up.

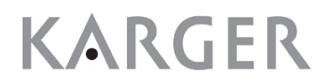




\section{Cellular Physiology Cell Physiol Biochem 2018;48:2205-2218 \begin{tabular}{c|c|c|c|c|} 
DOI: 10.1159/000492561 & O 2018 The Author(s). Published by S. Karger AG, Basel \\
mwwwkargercom/cpb
\end{tabular} and Biochemistry $\frac{\text { Published online: Augus }}{\text { Cheng et al.: miRNA-9 and miRNA-221 as Key Regulators of Breast Cancer Stem Cell-like }}$}

\section{Materials and Methods}

\section{Cell culture and transfection}

Breast cancer cell lines MCF-7 and MDA-MB-231 were purchased from the Bioresources Collection and Research Center (Hsinchu, Taiwan). Cells were maintained in Dulbecco's modified Eagle's medium (DMEM; Gibco, Carlsbad, CA) with 10\% fetal bovine serum (FBS, Gibco), $100 \mathrm{IU} / \mathrm{mL}$ penicillin G, and $100 \mathrm{~g} / \mathrm{mL}$ streptomycin in a humidified $37^{\circ} \mathrm{C}$ environment with $5 \% \mathrm{CO}_{2}$. Cells were seeded in 6-well plates at $5 \times 10^{5}$ cells per well for $24 \mathrm{~h}$ and grown to $60 \%$ confluency. Used at $20 \mathrm{nM}$, the mirVana ${ }^{\mathrm{TM}}$ miRNA mimics, miRNA inhibitors, or negative control (Ambion, Life Technologies, Austin, TX) formed transfection complexes with Lipofectamine $\AA^{2} 2000$ (Invitrogen, Carlsbad, CA) in a serum-free Opti-MEM $₫$ medium (Invitrogen) at $37^{\circ} \mathrm{C}$ for $24 \mathrm{~h}$. The medium was exchanged daily with fresh medium with $10 \%$ FBS. Cell lysates were harvested post-transfection for total RNA isolation.

\section{SP cell sorting}

We followed detailed protocols for SP cell sorting [17]. Briefly, the dissociated cells were suspended at a concentration of $2 \times 10^{6} \mathrm{cells} / \mathrm{mL}$ in SP medium (calcium- and magnesium-free Hanks' balanced salt solution with $2 \%$ FBS, $1 \%$ penicillin/streptomycin, and 10 mM HEPES, pH 7.4. Hoechst 33342 (Sigma-Aldrich) was optimized (concentration of $5 \mu \mathrm{g} / \mathrm{mL}$ ) in SP medium with intermittent mixing for $90 \mathrm{~min}$ at $37^{\circ} \mathrm{C}$. The specific ABCG2 inhibitor, reserpine (50 $\mu \mathrm{M}$ final concentration; Sigma-Aldrich), was introduced prior to the addition of Hoechst 33342 to inhibit dye efflux. The dye Hoechst 33342 was excited at a wavelength of $355 \mathrm{~nm}$, and fluorescence profiles were measured by dual-wavelength analysis with emission for Hoechst 33342 blue at $450 \mathrm{~nm}$ and Hoechst 33342 red at $675 \mathrm{~nm}$. After that, SP and non-SP cells were separately maintained on ice in the dark for fluorescenceactivated cell sorting (FACS Digital Vantage/Diva cell sorter; BD Biosciences, San Jose, CA) (Fig. 1).

\section{Sphere passage}

Spheres formed of SP cells in culture were collected and washed to remove serum and then incubated in serum-free DMEM containing $100 \mathrm{IU} /$ $\mathrm{mL}$ penicillin, $100 \mu \mathrm{g} / \mathrm{mL}$ streptomycin, $\mathrm{N}-2$ plus media supplement (R\&D Systems Inc. Minneapolis MN), $10 \mathrm{ng} / \mathrm{mL}$ EGF, $20 \mathrm{ng} / \mathrm{mL}$ bFGF (Invitrogen), and $4 \mathrm{mg} / \mathrm{mL}$ heparin (Sigma). For serial passage of spheroid cells, single cells were cultured in lowattachment 6-well plates (Corning Inc., Corning, $\mathrm{NY}$ ), and the cell density at each passage was adjusted to $5 \times 10^{3}$ cells $/ \mathrm{mL}$ in the serum-free medium.

\section{Wound healing assay}

Approximately $1.5 \times 10^{5}$ cells per well were seeded in 24-well culture plates. Cells were transfected with miRNA mimics or miRNA inhibitors, after which a sterile $10-\mu \mathrm{L}$ tip was used to scratch the monolayer of cells to create a narrow wound-like gap. The plate was kept at $37^{\circ} \mathrm{C}, 5 \%$ $\mathrm{CO}_{2}$ for $24 \mathrm{~h}$. Microscopy images of a representative field of the cell-free space were taken at 0 and $18 \mathrm{~h}$ after the scratch, and cell migration distance was calculated with Image Pro plus software (Media Cybernetics, Silver Spring, MD).

\section{KARGER}

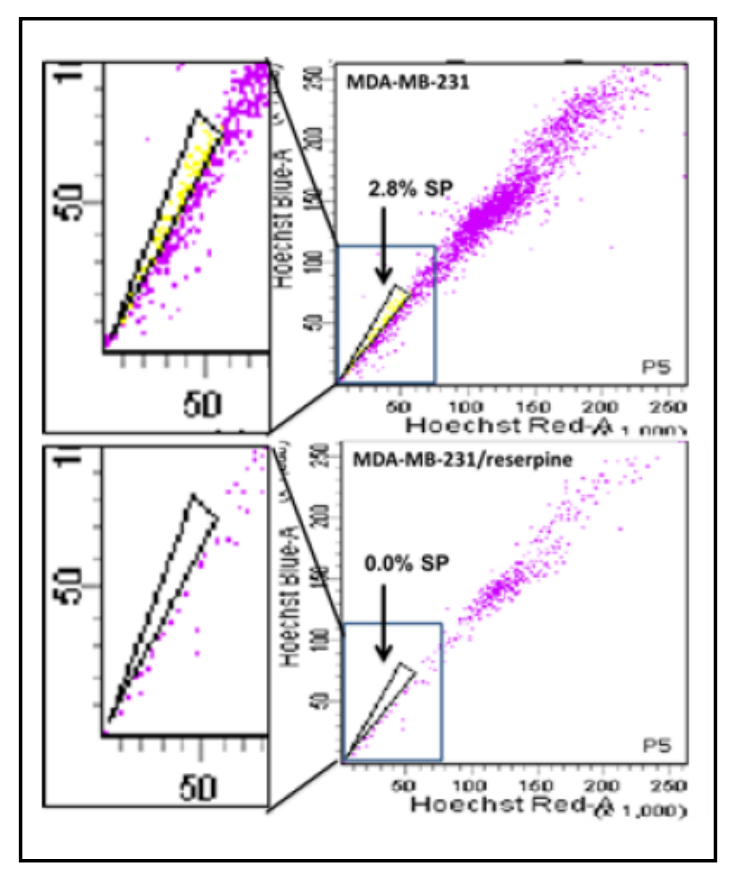

Fig. 1. SP cells form in a breast cancer cell line. Flow cytometry analysis of cultured MDA-MB-231 breast cancer cells revealed that side-population (SP) cells effluxed Hoechst 33342 dye. Cells were stained with Hoechst 33342 dye in the absence (upper) or presence (lower) of $50 \mu \mathrm{M}$ reserpine, and dye efflux from cells was assessed by fluorescence-activated cell sorting. 


\section{Cellular Physiology Cell Physiol Biochem 2018;48:2205-2218 \\ \begin{tabular}{l|l|l} 
and Biochemistry Published online: August 10, 2018 & $\begin{array}{l}\text { C) } 2018 \text { The Author(s). Published by S. Karger AG, Basel } \\
\text { www.karger.com/cpb }\end{array}$ \\
\hline
\end{tabular}}

Cheng et al.: miRNA-9 and miRNA-221 as Key Regulators of Breast Cancer Stem Cell-like

Cells

\section{Invasion/migration assay}

Cells were trypsinized and seeded at $5 \times 10^{4}$ cells per well into 48-well modified Boyden chambers (Neuro Probe Inc., Cabin John, MD) with polycarbonate membranes (8- $\mu$ m pore size) to evaluate their invasion (with Matrigel ${ }^{\mathrm{TM}}, \mathrm{BD}$, Biosciences) and migration (without Matrigel ${ }^{\mathrm{TM}}$ ) capabilities for $12-16 \mathrm{~h}$. Transwell migration upper chambers were filled with culture medium containing $2 \%$ FBS, and the lowerchamber medium contained 10\% FBS. The chamber was stained with Giemsa for $1 \mathrm{~h}$ and then washed twice with distilled/deionized $\mathrm{H}_{2} \mathrm{O}$. Non-migrating cells were removed from the cotton, and migrated cells were counted in five randomly selected fields from each well using a light microscope (Olympus Ckx41; Tokyo, Japan).

\section{Western blotting}

Western blotting was carried out as described [18]. Proteins that had been separated by SDS-PAGE were transferred onto a polyvinylidene difluoride membrane that was then subjected to western blotting with an appropriate primary antibody against the following: human vimentin (Cell Signaling Technology, Danvers, MA), fascin and $\beta$-catenin (Santa Cruz Biotechnology, Dallas, TX), and Claudin-1 (CLDN-1) and CLDN-2 (Novus Biologicals, Littleton, CO). The antibody against GAPDH (Cell Signaling Technology) served as the endogenous control to normalize the expression of proteins of interest. For western blotting, an appropriate horseradish peroxidase-conjugated secondary antibody was used, and each immunoreactive protein was visualized with an enhanced chemiluminescence assay (Western Blotting Luminol Reagent; Santa Cruz Biotechnology). Band intensity was quantified by densitometry (Digital Protein DNA Imagineware, Huntington Station, NY).

\section{Patients and tissue specimens}

All frozen-tissue specimens were histologically confirmed to be primary invasive ductal carcinoma of the breast and were from 206 patients enrolled between 1999 and 2005. All participants provided written informed consent to participate in this study. Considerations regarding methodological issues, including research design, sampling scheme, and consent procedure, were approved by the Ethics Committee of the Institutional Review Board at the Chung Shan Medical University Hospital, Taichung, Taiwan. During surgical intervention, freshly resected breast tumor tissues were immediately frozen in liquid nitrogen until analysis. None of the patients received neo-adjuvant treatment before primary surgery, thus avoiding any consequent effects on the expression levels of the miRNA examined. Tumor grade was categorized according to the Nottingham modification of the Scarff-Bloom-Richardson system [19], and tumor pathology was classified according to the sixth edition of the AJCC Cancer Staging Manual [20]. The presence of metastatic tumor cells in lymph nodes was scored by immunohistochemical staining of at least 10 lymph-node dissections from tumors of patients. Details of their clinicopathological features were obtained from hospital tumor registries.

Laser capture microdissection and quantitative PCR (qPCR) analysis

We followed detailed procedures for RNA isolation from cells collected by laser capture microdissection $[18,21]$. RNAs were extracted from laser capture microdissected samples from the tumor and adjacent nontumor breast tissue of each patient using the mirVana miRNA isolation kit, and the RNA concentration in each sample was quantified using a NanoDrop 1000 spectrophotometer (NanoDrop Technologies, Waltham, MA). A single-tube TaqMan ${ }^{\mathrm{TM}}$ MicroRNA assay (Applied Biosystems, Foster City, CA) was used to quantify mRNA level using the StepOnePlus ${ }^{\mathrm{TM}}$ instrument (Applied Biosystems); the sequences for probes and primer sets used to detect miR-9 (ID 000583) and miR-221 (ID 000524) in the MicroRNA assay were purchased from Applied Biosystems. The level of U6 small RNA (encoded by RNU6B) was stable and reproducible across tissue specimens and was applied to estimate differential expression of the miRNAs between tumor and non-tumor paired samples in each case. Relative expression levels were calculated using the $2^{-\Delta \Delta c t}$ method.

\section{Prognostic significance of miR-9/221 in breast cancer}

This study was dependent on a reliable follow-up system that we established and maintained to actively and regularly track cancer progression for our breast cancer patients [22]. Disease-free survival (DFS) was measured as the time from surgery to recurrence/mortality or the end of the study, and overall survival (OS) 
was calculated from the date of surgery to the date of disease-related death or date of the last follow-up for each patient, at which time 93\% (191 of 206) of patients were analyzed. For assessing the accuracy of the miRNA in demonstrating the progression of breast tumors, the diagnostic cut-off for miRNA was identified based on receiver-operating characteristic curves and the estimated area under the curve, to which an optimal cutoff point was applied to differentiate the increased level of each miRNA in tumors. The quantified miRNA levels were converted into binary measurements according these cutoffs. The odds ratio (OR) and 95\% confidence interval (CI) were estimated with a logistic regression model to investigate the association between clinical pathological parameters or prognostic features of tumors and the level of miR-9 and/or miR-221. We also used this system to examine whether overexpression of either of these two miRNAs could be prospectively associated with breast cancer progression using the eight-year OS and DFS as outcomes of interest. The hazard ratio (HR) and 95\% CI were estimated with the Cox proportional hazards model and Kaplan-Meier method, which were used to correlate OS and DFS with clinical pathological parameters or miRNA levels. All statistical tests were two-sided, and $P<0.05$ was considered statistically significant.

\section{Statistical analysis}

Data are presented as the mean \pm standard deviation (S.D.). For all groups, all cell-based experiments were performed in triplicate. The statistical significance of difference in results between test groups was assessed with an unpaired two-tailed Student's t-test, one-way ANOVA, Mann-Whitney $U$ test or Dunnett's test as appropriate. All statistical analyses were performed using SPSS version 19.0 (SPSS Inc., Chicago, IL). $P$-values are represented as $*,<0.05 ; * *,<0.01$; and ${ }^{* * *},<0.001$.

\section{Results}

Blockade of miR-9 and miR-221 decreases SP generation and inhibits breast cancer cell invasion/migration

We found that the endogenous expression of both miR-9 and miR-221 was significantly greater in the aggressive MDA-MB-231 breast cancer cell line than in the non-invasive MCF-7 breast cancer line (Fig. 2A). To determine whether there is a causal link between miR-9 and miR-221 expression and the abundance of cancer stem cell-like SP cells in breast cancer, we identified and purified SP cells using the dye Hoechst 33342 and fluorescence-activated cell sorting of breast cancer cells treated with reserpine. This SP sorting procedure revealed that the proportion of SP cells was significantly reduced in MDA-MB-231 cells transfected with a specific inhibitor of miR-9 (anti-miR-9) or miR-221 (anti-miR-221) (or both inhibitors) compared with a mock-transfected control (Fig. 2B and 2C). Upon transfection of cells with both miRNA inhibitors, the number of tumorsphere-forming MDA-MB-231 cells was reduced by $>80 \%$ together with a reduction in the transcription of the stemness markers CD133, Nanog, and Oct4 genes (Fig. 2D and 2E). Moreover, inhibition of miR-9 or miR-221 led to a diminution of the typical elongated and spindle-like fibroblastic phenotype of MDAMB-231 cells (Fig. 2G). In addition, transfection with either inhibitor dramatically decreased the motility of MDA-MB-231 SP cells (Fig. 2F) in conjunction with a 40-70\% decrease in their invasion capacity (Fig. 2H).

Overexpression of miR-9 and miR-221 enhances invasion and metastasis of MCF-7 SP cells

Because the levels of endogenous miR-9 and miR-221 were low in the non-invasive MCF-7 breast cancer cells, we investigated the effects of miR-9 and/or miR-221 mimics on these cells to elucidate the stem-cell mechanisms by which overexpression of miR-9 and miR-221 enhances invasion and metastasis of breast cancer. As expected, the percentage of SP cells was increased by $>4$-fold in miR-9/221-transfected MCF-7 cells compared with mock-transfected controls (miR mimic negative control, NC; Fig. 3A and 3B). These results were reinforced by wound-healing assays of the miR-9/221-transfected MCF-7 SP cells, which revealed a 2- to 3-fold increase in motility (Fig. 3C) and a 3- to 5.5-fold increase in invasion capacity (Fig. 3D). Moreover, the levels of the mesenchymal proteins: vimentin, fascin, and $\beta$-catenin were higher in MCF-7 cells transfected with both miR-9 and miR-221 
Fig. 2. Inhibition of miR-9 and miR221 suppresses the generation of side-population (SP) cells and decreases the stem cell-like properties of breast cancer SP cells. (A) miR-9 and miR221 levels were s i gn ificantly increased

highly aggressive M D A - M B - 231 breast cancer cells as compared with a moderate decrease in noninvasive MCF-7 breast cancer cells. TaqManbased real-time PCR was used to quantify relative expression of the miRNAs along with RNU6B. (B) MDA-MB-231 cells were transfected with the inhibitor negative control (anti-miR (NC)), anti-miR-9 or anti-miR-221, and miRNA expression
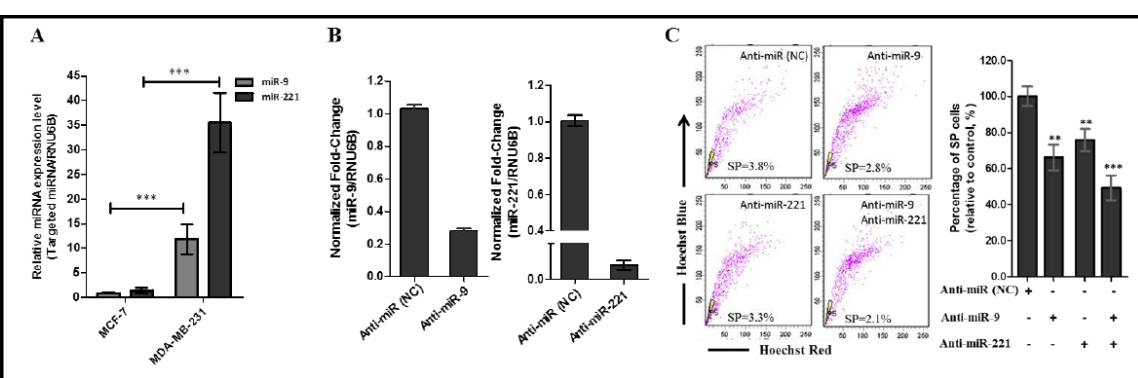

D
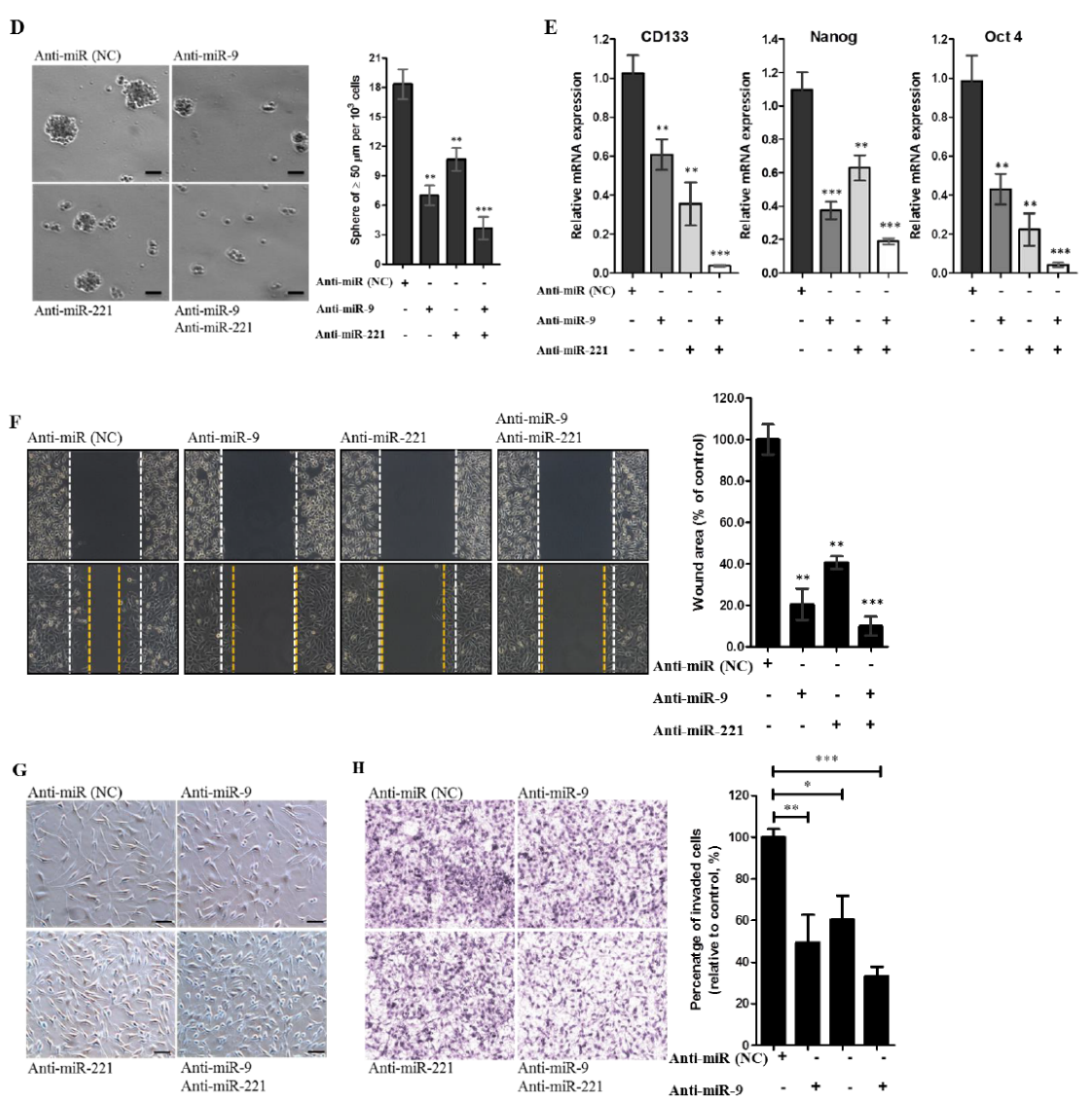

nti-miR-221 - - +

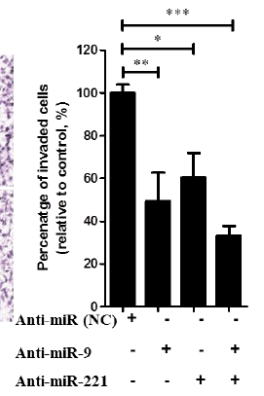

was assessed with

real-time reverse transcription-PCR. (C) SP cells were analyzed with fluorescence-activated cell sorting and the efflux of Hoechst 33342 dye (left panel). Shown are the percentages of SP cells generated from MDAMB-231 cells that had been transfected with an anti-miRNA oligonucleotide [(negative control, anti-miR (NC), anti-miR-9, anti-miR-221, or both; right panel)]. (D) SP cells were cultured in suspension to form tumorspheres. Scale bar, $50 \mu \mathrm{m}$ (left panel). Spheres were counted among $1 \times 10^{3}$ cells per condition for MDA-MB-231 cells transfected with the miRNA inhibitors as indicated (right panel). (E) qPCR results revealed lower levels of mRNAs encoding CD133, Nanog, and Oct4 as compared with anti-miR (NC). (F) Representative images of wound-healing assays for MDA-MB-231 cells; images were acquired at $0 \mathrm{~h}$ (white line) and $18 \mathrm{~h}$ (yellow line) after scarification (left panel). Quantification of wound-healed area for MDA-MB-231 cells was assessed (right panel). (G) Representative images of the phenotypic change from mesenchymal to cobblestone-like epithelial cells as seen in SPs treated with the miRNA inhibitors as indicated. Scale bar, $50 \mu \mathrm{m}$. (H) Schematic representation of the invasive capacity of SP cells was plated on

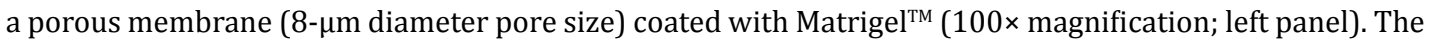
invading tumor cells were evaluated with a Boyden chamber assay and counted in five random fields of view (right panel). ${ }^{*} \mathrm{P}<0.05,{ }^{* *} \mathrm{P}<0.01,{ }^{* * *} \mathrm{P}<0.001$.

\section{KARGER}


mimics than in the mock-transfected control cells (Fig. 3E).

In parallel, use of specific inhibitors of the two miRs (i.e., anti-miR-9 and anti-miR-221) resulted in increased expression of the epithelial proteins CLDN-1 and CLDN-2 in the E-cadherin-deficient MD-MBA-231 cells compared with expression in the negative control cells (NC; Fig. 3E). Again, these findings supported our hypothesis that miR-9 and miR-221 enable breast cancer cells to generate SP cells with stem cell-like characteristics, which is considered a prerequisite for retention of invasive potential during the EMT.

Overexpression of miR-9/221 is associated with poor prognosis of breast cancer patients

Given that overexpression of the two miRNAs in vitro led to the generation of cancer stem cell-like cells that promote tumor invasion, we examined the association between miR-9 and miR-221 levels and clinicopathological characteristics of breast cancer. For this

Fig. 3. Delivery of miR-9 and miR-221 oligonucleotides enhances the motility and invasiveness of MCF-7 SP cells. (A) qPCR of miR9 and miR-221 levels in MCF7 cells following transfection with the miRNA mimics and negative control [miRNA mimic (NC)]. (B) SPs of MCF-7 origin transfected with miR-9, miR-221, both miRNA mimics or negative control as indicated (left panel). Multicellular tumor spheroid formation by breast cancer cells were calculated at $72 \mathrm{~h}$ in the presence of different miRNA mimics (right panel). (C) The left panel shows
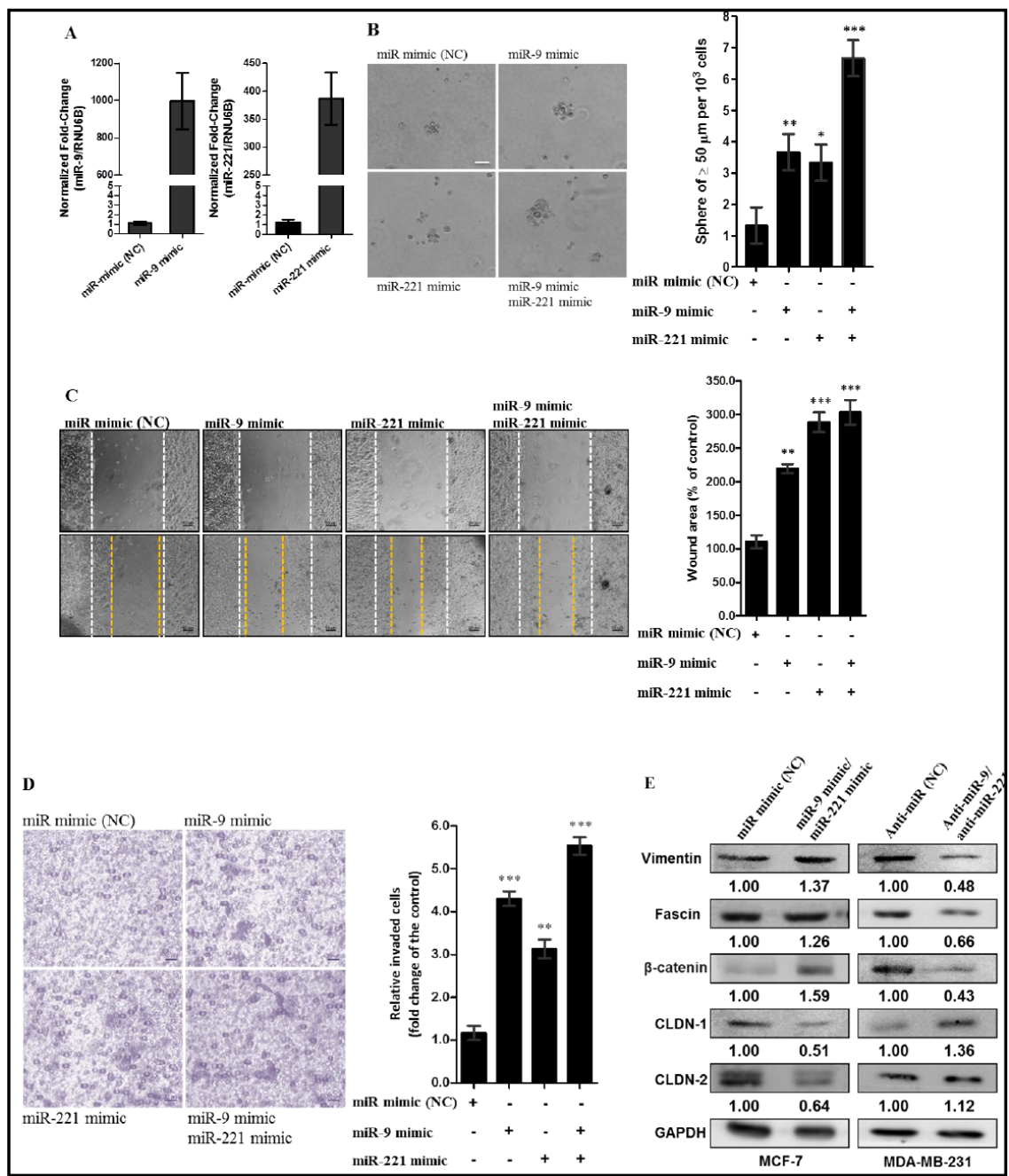

wo und-he aling

assays for MCF-7 SP cells; images were acquired at $0 \mathrm{~h}$ (white line) and $18 \mathrm{~h}$ (yellow line) after scarification, and quantification of the wound-healed area for MCF-7 cells is shown in the right panel. (D) Boyden chamber assay using membranes coated with matrigel to measure the invasiveness (left panel) of MCF-7 SPs. The invading cells were counted in eight randomly chosen microscope fields (right panel). Data represent the mean \pm S.D. from three independent experiments. (E) Western blotting for epithelial protein markers [Claudin-1 (CLDN-1) and CLDN-2] and mesenchymal protein markers (vimentin, fascin, and $\beta$-catenin) in MCF-7 cells (left panel) transfected with miRNA mimics or in MDA-MB-231 cells (right panel) treated with miRNA inhibitors. GAPDH was used as an internal control. ${ }^{*} \mathrm{P}<0.05,{ }^{* *} \mathrm{P}<0.01,{ }^{* * *} \mathrm{P}<0.001$. 


\section{Cellular Physiology Cell Physiol Biochem 2018;48:2205-2218 \begin{tabular}{ll|l} 
DOI: 10.1159/000492561 & $\begin{array}{l}\text { O 2018 The Author(s). Published by S. Karger AG, Basel } \\
\text { www.karger.com/cpb }\end{array}$
\end{tabular}

translational application, 206 breast cancer patients diagnosed with invasive ductal carcinoma were included, and the patient clinical characteristics are shown in Table 1.

We used laser capture microdissection to isolate tumor cells from tissue specimens to avoid contamination with normal cells and then quantified the level of individual miRNAs by real-time qPCR. Comparative quantification of miRNA levels revealed that miR-9 and miR-221 were expressed at significantly higher levels in tumors compared with matched-pair nontumor tissue (normalized against RNU6B; mean values $(-\Delta \mathrm{Ct})$ for miRNA level among tumors and non-tumor tissues were 3.06 vs. 1.78, respectively, for miR-9, $P<0.0001$, and 1.47 vs. 0.50 for miR-221, $P=0.0002$; Fig. 4 A). To establish the prognostic significance of both miRNAs, we determined the cutoff for expression of each miR using receiver-operating characteristic (ROC) curves to discriminate late-stage breast tumors (stage III/IV) from early-stage
Table 1. Clinicopathological characteristics of breast cancer patients included in our study. NA, data not available; NT, no treatment. ER, PR or HER2 status: negative, $<30 \%$ of cells stained; positive, $\geq 30 \%$ of cells stained

\begin{tabular}{lc}
\hline Clinicopathological characteristics & $\mathrm{N}(\%)$ \\
\hline Age (years, mean \pm S.D.) & $51.1 \pm 11.6$ \\
Tumor size (mm) & $110(53.4)$ \\
$\leq 20$ & $96(46.4)$ \\
$>20$ & \\
Histologic grade & $23(11.2)$ \\
Well differentiated & $95(46.1)$ \\
Moderately differentiated & $88(42.7)$ \\
Poorly differentiated & \\
AJCC stagea & $69(33.5)$ \\
I & $77(37.4)$ \\
Ila & $28(13.6)$ \\
IIb & $26(12.6)$ \\
III & $6(2.9)$ \\
IV & \\
Tumor extension in metastatic lymph node & $109(52.9)$ \\
Negative (No) & $97(47.1)$ \\
Positive (N $\mathrm{N}_{2}$ ) & \\
ER & $99(48.5)$ \\
Positive & $105(51.5)$ \\
Negative & 2 \\
NA & \\
PR & $93(45.6)$ \\
Positive & $111(54.4)$ \\
Negative & 2 \\
NA & \\
HER2 & $90(45.9)$ \\
Positive & $106(54.1)$ \\
Negative & 10 \\
NA & \\
Therapy & \\
Chemotherapy & \\
Hormone therapy & $15(27.2)$ \\
Radiotherapy & $4(1.3)$ \\
Chemotherapy (with radiotherapy or hormone therapy) & $47(22.8)$ \\
Radiotherapy and hormone therapy & $11(5.3)$ \\
Combined therapy & $56(27.2)$ \\
NT & $10(4.9)$ \\
NA & $7(3.4)$ \\
\hline & \\
& \\
&
\end{tabular}

Fig. 4. The mean proportion of miR-9 or miR-221 overexpressing cells was significantly greater in tumor samples compared non-tumor samples. (A) The cellular level of miR-9 (left panel) and miR-221 (right panel) was determined by qPCR in microdissected tumor cells and adjacent non-tumor cells from primary tumors of breast cancer patients. The results were normalized to those for RNU6B and were calculated using the comparative CT method. Each dot represents a case, and the line represents the mean for each subgroup. Differences were examined using the Mann-Whitney U test. (B) Receiver operating characteristic (ROC) curves constructed for the multivariate model of miRNA expression in differentiating late-stage breast cancer cells from early-stage breast cancer. Area under the curve (AUC) for miR-9 (left panel) and miR-221 (right panel).

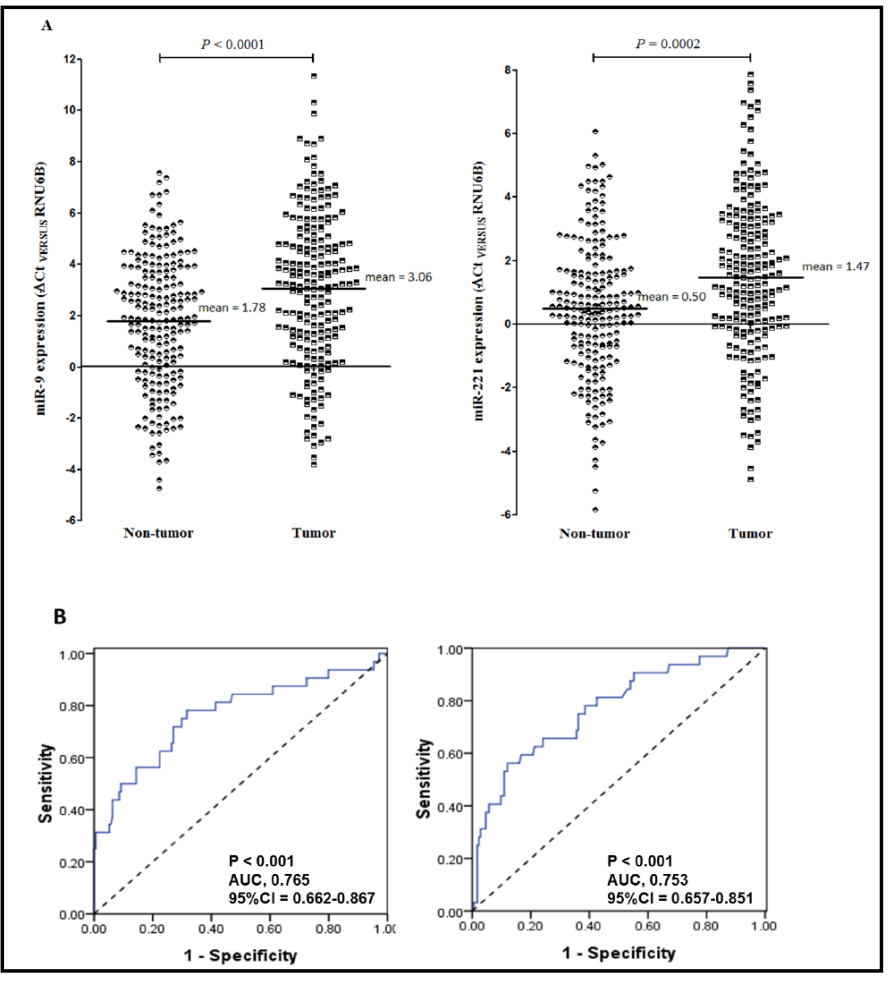


Cheng et al.: miRNA-9 and miRNA-221 as Key Regulators of Breast Cancer Stem Cell-like Cells

tumors (stage I/II) (Fig 4B). Based on these curves, we defined "overexpression" of miR-9 and miR-221 by comparing the levels of these miRs in tumor cells relative to non-tumor cells, which revealed a 4.35 -fold cutoff value for miR-9 ($\Delta \Delta \mathrm{Ct}=2.12$ ) and 5.10 -fold cutoff value for miR-221 ($\Delta \Delta \mathrm{Ct}=2.35$ ). These cutoff values were used to assess the association between miRNA overexpression and clinicopathological features, manifesting as risk elevation for miR-9 or miR-221 in tumors, with subsequent assignment of each tumor as poorly differentiated, late stage, and nodal involvement (positive for lymphnode metastasis, LNM) after adjusting for age and expression status of estrogen receptor (ER), progesterone receptor (PR), and human epidermal growth-factor receptor 2 (HER2) in a multivariate logistic regression analysis (all $P<0.05$; Table 2).

We found that both miRNAs were overexpressed in advanced-stage breast tumors, and this predicted a poor clinical outcome for those patients. As expected, tumor cell invasiveness was most prevalent in the subgroup that co-overexpressed both miR-9 and miR-221, as assessed with a multivariate analysis $(P<0.05$; Table 3$)$. The use of a dummy-variable coding scheme and the $\beta$ estimate from the regression model revealed a significant tendency for elevated risk of breast cancer development in that patient subgroup (all $P_{\text {trend }}<0.05$, Table 3).

\section{Overexpression of miR-9 and miR-221 predicts poor survival of breast cancer patients}

We evaluated the significance of miR-9/miR-221 overexpression as a predictor of clinical outcomefor breastcancer patients during an eight-year follow-up. Similar toknown prognostic factors, including tumor size, histology grade, tumor stage, and tumor extension to lymph nodes (Fig. 5A-H), the primary tumors that carried both miR-9 and miR-221 overexpression were predictive of shorter OS and DFS, as determined by significant differences in the two Kaplan-Meier curves with the Bonferroni correction (Fig. 5I and 5J; $P$-values for the log rank test were smaller than 0.001 and 0.035 for OS and DFS, respectively). Of the prognostic factors, tumors that were poorly differentiated, late stage or LNM-positive were associated with disease mortality as assessed with a univariate Cox proportional regression analysis $(P$ $<0.05$, Table 4). Moreover, comparison of the miRNA expression profiles for the breast cancer

Table 2. Correlations between clinicopathological features and miRNA overexpression in patients with breast cancer $* \mathrm{P}<0.05,{ }^{* *} \mathrm{P}<0.01,{ }^{* * *} \mathrm{P}$ $<0.001$ compared with the reference (Ref) group

\begin{tabular}{|c|c|c|c|c|}
\hline \multirow{2}{*}{ Clinicopathological features } & \multicolumn{4}{|c|}{ miRNA overexpression (fold increase in tumor cells relative to non-tumor cells) } \\
\hline & $\operatorname{miR}-9(>4.35)$ & OR $(95 \% \mathrm{CI})$ & miR-221 $(>5.10)$ & OR $(95 \% \mathrm{Cl})$ \\
\hline \multicolumn{5}{|l|}{ Tumor size $(\mathrm{mm})$} \\
\hline$\leq 20$ & $27 / 110(24.5 \%)$ & 1.00 (Ref) & $19 / 110(17.3 \%)$ & 1.00 (Ref) \\
\hline$>20$ & $47 / 96(49.0 \%)$ & $2.95(1.63-5.32)^{* *}$ & $23 / 96(24.0 \%)$ & $1.51(0.80-2.98)$ \\
\hline \multicolumn{5}{|l|}{ Tumor grade } \\
\hline $\begin{array}{l}\text { Well/moderately } \\
\text { differentiated }\end{array}$ & $32 / 118(27.1 \%)$ & 1.00 (Ref) & $17 / 118(14.4 \%)$ & 1.00 (Ref) \\
\hline Poorly differentiated & $42 / 88(47.7 \%)$ & $2.45(1.37-4.39)^{* *}$ & $25 / 88(28.4 \%)$ & $2.36(1.18-4.71)^{*}$ \\
\hline \multicolumn{5}{|l|}{ Tumor stage } \\
\hline I/II & $54 / 174(31.0 \%)$ & 1.00 (Ref) & $27 / 174(15.5 \%)$ & 1.00 (Ref) \\
\hline III/IV & $20 / 32$ (62.5\%) & $3.71(1.69-8.12)^{* *}$ & $15 / 32$ (46.9\%) & $4.80(2.14-10.76)^{* * *}$ \\
\hline \multicolumn{5}{|l|}{ LNM } \\
\hline $\mathrm{N}_{0}$ & $23 / 109$ (21.1\%) & 1.00 (Ref) & $15 / 109(13.8 \%)$ & 1.00 (Ref) \\
\hline $\mathrm{N}_{1} / \mathrm{N}_{2}$ & $51 / 97$ (52.6\%) & $4.14(2.26-7.62)^{* * * *}$ & $27 / 93(27.8 \%)$ & $2.42(1.20-4.88)^{*}$ \\
\hline
\end{tabular}

Table 3. Effect of miRNA co-overexpression on tumors of patients with a poor prognosis $(+)$ Overexpression of an individual miRNA; (-) normal expression of the miRNA. The association between gene interactions $ß$ estimate from the logistic regression model. $* \mathrm{P}<0.05, * * \mathrm{P}<0.01, * * * \mathrm{P}$ $<0.001$ compared with the reference Ref, miR-9(-)/miR-221(-) cells.

\begin{tabular}{|c|c|c|c|c|}
\hline \multirow[b]{2}{*}{ Overexpressed miRNA(s) } & \multicolumn{4}{|c|}{ Prognostic features } \\
\hline & $\begin{array}{c}\text { Large tumor size } \\
\text { OR }(95 \% \mathrm{CI})^{\S}\end{array}$ & $\begin{array}{l}\text { Poor differentiation } \\
\text { OR }(95 \% \mathrm{CI})\end{array}$ & $\begin{array}{c}\text { Late-stage } \\
\text { OR }(95 \% \mathrm{Cl})\end{array}$ & $\begin{array}{l}\text { LNM-positive } \\
\text { OR }(95 \% \mathrm{CI})\end{array}$ \\
\hline miR-9(-)/miR-221(-) & 1.00 (Ref) & 1.00 (Ref) & 1.00 (Ref) & 1.00 (Ref) \\
\hline $\begin{array}{l}\text { miR-9(-)/miR-221(+) } \\
\text { miR-9(+)/miR-221(-) }\end{array}$ & $2.54(1.37-4.71)^{* *}$ & $1.89(1.02-3.49)^{*}$ & $3.14(1.25-8.01)^{*}$ & $3.36(1.80-6.29)^{* *}$ \\
\hline miR-9(+)/miR-221(+) & $3.01(1.21-7.38)^{*}$ & $4.86(1.86-12.72)^{* *}$ & $11.21(3.82-32.93)^{* * *}$ & $6.24(2.28-17.03)^{* * *}$ \\
\hline One additional risk miRNAa & $1.95(1.28-2.95)$ & $2.09(1.38-3.18)$ & $3.34(1.94-5.73)$ & $2.80(1.79-4.38)$ \\
\hline
\end{tabular}


Table 4. Predictors of poor OS and DFS for patients with breast cancer. Estimation of the hazard ratio (HR) for patients with invasive ductal carcinoma having a more than eight-year follow-up was done with the Cox proportional regression analysis. Patients for whom miR-9 and miR-221 were not overexpressed in tumors served as the reference group

\begin{tabular}{lcccc}
\hline $\begin{array}{l}\text { Univariate regression analysis } \\
\text { Covariates }\end{array}$ & OS & \multicolumn{2}{c}{ DFS } \\
\hline Tumor size & $1.97(0.90-4.45)$ & 0.09 & $2.05(0.84-5.02)$ & 0.12 \\
Histology grade & $2.40(1.08-5.31)$ & 0.03 & $2.27(0.93-5.54)$ & 0.07 \\
Tumor stage & $6.42(2.84-14.53)$ & $<0.001$ & $4.77(1.87-12.12)$ & 0.002 \\
LNM-positive & $2.90(1.25-6.73)$ & 0.01 & $2.58(1.03-6.48)$ & 0.04 \\
ER & $1.67(0.74-3.79)$ & 0.22 & $2.25(0.86-5.87)$ & 0.10 \\
PR & $1.85(0.80-4.29)$ & 0.15 & $1.30(0.53-3.18)$ & 0.57 \\
HER2 & $0.98(0.41-2.37)$ & 0.97 & $1.47(0.53-4.05)$ & 0.46 \\
One additional risk miRNA & $2.69(1.59-4.54)$ & $<0.001$ & $1.95(1.09-3.50)$ & 0.03 \\
Multivariate regression & & & & \\
analysis & & & & \\
Covariates & & & & \\
Histology grade & HR (95\% CI) & P-value & HR (95\% Cl) & P-value \\
Tumor stage & $1.21(0.49-2.98)$ & 0.68 & $1.49(0.57-3.92)$ & 0.42 \\
LNM-positive & $3.97(1.38-11.47)$ & 0.01 & $2.82(0.88-9.00)$ & 0.08 \\
One additional risk miRNA & $1.18(0.39-3.19)$ & 0.85 & $1.36(0.44-4.21)$ & 0.59 \\
\hline
\end{tabular}

patients revealed that those who carried an increasing number of tumors with miR-9 and miR-221 overexpression were associated with decreased OS (hazard ratio [HR] 2.69; 95\% confidence interval [CI], 1.59-4.54, $P_{\text {trend }}<0.001$ ) and DFS (HR 1.95; 95\%CI, 1.09-3.50, $P_{\text {trend }}=0.025$ ). A multivariate Cox proportional hazard regression analysis revealed that interactions of miR- 9 and miR-221 overexpression remained an independent predictor of poor OS $(\mathrm{HR}=$ $\left.2.02, P_{\text {trend }}=0.017\right)$ of breast cancer patients (Table 4).

\section{Discussion}

It is well established that the EMT correlates with epithelial cell plasticity and is associated with the characteristics of latestage tumorigenesis, such as local tumor invasion and metastasis. A growing body of

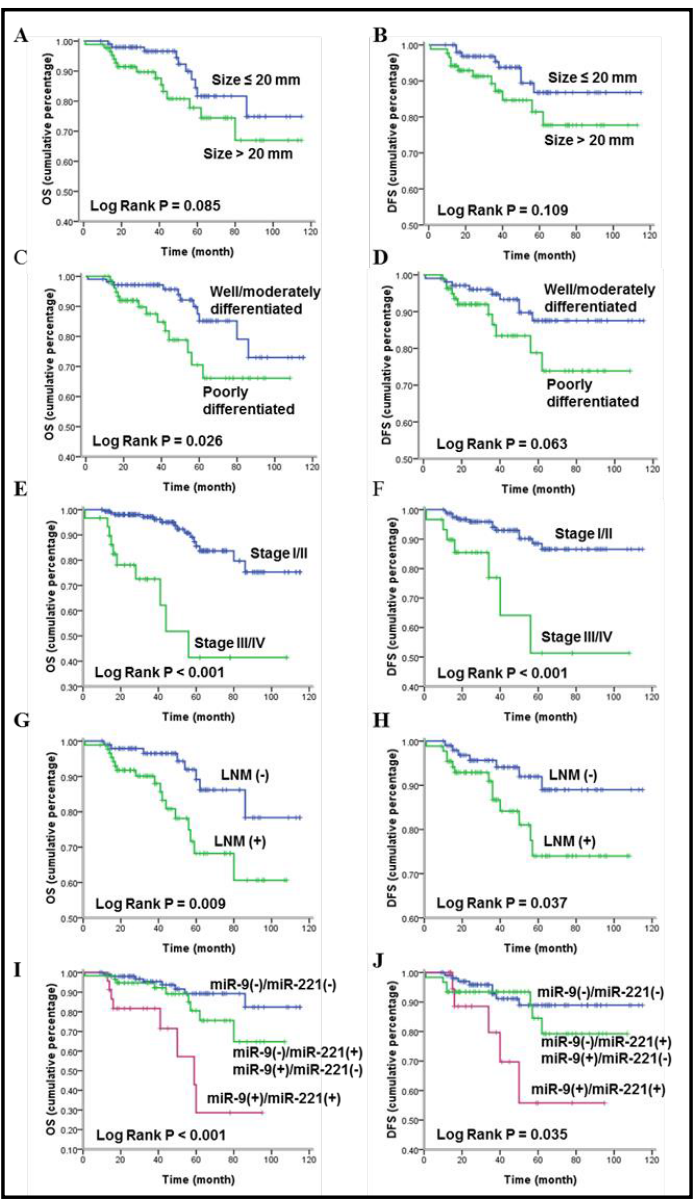

Fig. 5. Overexpression of miR-9 and miR-221 correlates with poor prognosis for breast cancer patients. Kaplan-Meier curves for OS and DFS for all patients studied, according to different clinicopathological parameters, including patients with tumors of large size $(A, B)$, with poor differentiation $(\mathrm{C}, \mathrm{D})$, classified as late stage $(\mathrm{E}$, F), and LNM-positive (G, H). A tendency towards a greater number of cells with miR-9 and miR-221 overexpression correlated with decreased OS in (I) or DFS in (J) of patients with breast cancer. (+) overexpression of an individual miRNA; (-) normal expression of the miRNA. evidence suggests that activation of the EMT has a close connection with the development of stem cell-like characteristics of mesenchymal cells in the cancer niche [23, 24]. In our present study, we first assessed the generation of SP cells, which was promoted by miR-9 and miR221 overexpression in non-invasive MCF-7 cells. We also found that the wounded area in our wound-healing assay was reduced in cells transfected with miR-9 or miR-221 as compared with miR mimic-transfected control cells. By contrast, knockdown of miR-9 and miR-221 led to decreased production of SP cells and resulted in decreased invasiveness of MDA-MB-231 breast cancer cell line. Similarly, in studies of recurrent glioma, SP cells were screened for hierarchical organization within the new tumor clone because this subpopulation has stem cell-like characteristics and plasticity that are critical for tumor reprogramming to a 
more aggressive tumor phenotype $[25,26]$. Taken together, these findings provide evidence for a causal link between the regulatory role of miRNAs in establishing the cancer stemcell phenotype, highlighting the relevance of differential expression of such miRNAs in a paradigm that distinguishes between benign and invasive features of carcinomas, including those of breast cancer, based on the generation of SP cells.

Studies have demonstrated that cancer cells acquire the ability to invade and disseminate via dysregulation of miRNA expression, which promotes the EMT [13, 27-29]. Increased levels of miR-9 and miR-221 in tumor cells are reportedly associated with an increased risk for tumorigenesis and greater resistance to chemotherapeutics, as demonstrated in multiple primary cancers [15, 30-32]. Recent work predicted targets of miR-9 and defined their functions, such as EMT induction by targeting the CDH1 mRNA [33, 34], mediation of temozolomide resistance of glioblastoma multiforme cells [35, 36], and SP expansion and metastasis through loss of $\alpha$-catenin in squamous cell carcinoma [32]. Moreover, epigenetic modulation of miR-221 contributes to stemness by decreasing DNMT3b expression and promotes cell outgrowth and invasiveness of human breast cancer stem cells via downregulation of PTEN and Trichorhinophalangeal syndrome type 1 (TRPS1) $[16,37,38]$. Our present results demonstrate that induction of miR-9/221 promotes the generation of cancer stem cell-like cells and help explain the heterogeneity of the invasion/dissemination capacity of SP cells present in breast cancer niches. Notably, recent reports have shown that delivery of miR-9 in tumor tissues in vivo could reduce angiogenesis and metastasis in gastric, melanoma, and nasopharyngeal carcinomas [39-41]. These discrepancies in the reported results may be due to differences in the extracellular microenvironment that tumor cells encounter because of tissue-specific regulation. Consequently, the shift of the paradigm of cancer-related association studies from a single candidate miRNA to multiple miRNAs, as was the case in our present study of breast cancer patients, is helping define prognostic signatures that can be validated in different cancer types.

The use of ER, PR, and HER2 has become a common and acceptable way for clinicians to predict breast cancer prognosis and prescribe a suitable therapeutic regimen for women living with the disease $[42,43]$. A recent investigation of miRNAs in stem-cell biology revealed the involvement of miR-200 in the organization of miRNA clusters and its differential expression in human breast cancer stem cells compared with normal mammary stem cells; therefore, a better understanding of the molecular mechanisms underlying the miR-200 family miRNAs with respect to how their cellular levels and consequent loss of control of self-renewal and EMT in breast cancer stem cell-like cells can predict patient prognosis [44]. Hereby, we expanded our previous dataset from a cell model to clinical observation to demonstrate that the prognostic significance of miR- 9 and miR-221 overexpression in breast cancer progression is independent of ER, PR, and HER2, as demonstrated by our findings, as follows. First, we found that elevated cellular levels of miR-9 and miR-221 could drive cancer stemness and contribute to the invasiveness in MCF-7 cells that expressed ER/PR/HER2. Second, decreased expression of both miRNAs reflects a divergence of cancer stemness in a triple-negative breast cancer cell line, such as MDA-MB-231, to inhibit cell invasion and migration through repression of the EMT. Third, within the confines of the reliability of the inferred statistical significance of the clinical prognosis, the data obtained from our breast cancer cohort revealed that miR- 9 and miR-221 are promising biomarkers that could clearly delineate the chance for survival and adjusted mortality after simultaneously considering the immunohistochemical markers of ER, PR and HER2. These findings are consistent with previous reports of miR-9 and miR-221 overexpression in primary tumors from patients with subsequent metastasis as compared with those of metastasis-free patients across several cancer types [45-48] as well as prognostic implications for recurrence in patients with papillary thyroid carcinoma [49]. Collectively, these findings shed light on the potential value of miR-9 and miR-221 testing with regard to helping clinicians establish the most effective therapeutic regimen for their breast cancer patients. 


\section{Cellular Physiology Cell Physiol Biochem 2018;48:2205-2218 \begin{tabular}{ll|l} 
and Biochemistry Published online: August 10, 2018 & $\begin{array}{l}\text { (c) } 2018 \text { The Author(s). Published by S. Karger AG, Basel } \\
\text { www.karger.com/cpb }\end{array}$
\end{tabular}

\section{Acknowledgements}

We sincerely appreciate Ms. Show-Ling Yang for her assistance in organizing our study specimens. This work was supported by research grant NSC102-2628-B-040-002-MY3 from the Ministry of Science and Technology, Taipei, Taiwan, ROC.

\section{Disclosure Statement}

No conflict of interests exists.

\section{References}

1 Rakha EA, El-Sayed ME, Menon S, Green AR, Lee AH, Ellis IO: Histologic grading is an independent prognostic factor in invasive lobular carcinoma of the breast. Breast cancer Res Treat 2008;111:121-127.

2 Jiang D, Zhao N: A clinical prognostic prediction of lymph node-negative breast cancer by gene expression profiles. J Cancer Res Clin Oncol 2006;132:579-587.

3 Mimeault M, Batra SK: Altered gene products involved in the malignant reprogramming of cancer stem/ progenitor cells and multitargeted therapies. Mol Aspects Med 2014;39:3-32.

4 Nakanishi T, Chumsri S, Khakpour N, Brodie AH, Leyland-Jones B, Hamburger AW, Ross DD, Burger AM: Side-population cells in luminal-type breast cancer have tumour-initiating cell properties, and are regulated by HER2 expression and signalling. Br J Cancer 2010;102:815-826.

-5 Zhou S, Schuetz JD, Bunting KD, Colapietro AM, Sampath J, Morris JJ, Lagutina I, Grosveld GC, Osawa M, Nakauchi H, Sorrentino BP: The ABC transporter Bcrp1/ABCG2 is expressed in a wide variety of stem cells and is a molecular determinant of the side-population phenotype. Nat Med 2001;7:1028-1034.

-6 Visvader JE, Lindeman GJ: Cancer stem cells in solid tumours: accumulating evidence and unresolved questions. Nat Rev Cancer 2008;8:755-768.

7 Al-Hajj M, Wicha MS, Benito-Hernandez A, Morrison SJ, Clarke MF: Prospective identification of tumorigenic breast cancer cells. Proc Natl Acad Sci USA 2003;100:3983-3988.

8 Mani SA, Guo W, Liao MJ, Eaton EN, Ayyanan A, Zhou AY, Brooks M, Reinhard F, Zhang CC, Shipitsin M, Campbell LL, Polyak K, Brisken C, Yang J, Weinberg RA: The epithelial-mesenchymal transition generates cells with properties of stem cells. Cell 2008;133:704-715.

-9 Pece S, Tosoni D, Confalonieri S, Mazzarol G, Vecchi M, Ronzoni S, Bernard L, Viale G, Pelicci PG, Di Fiore PP: Biological and molecular heterogeneity of breast cancers correlates with their cancer stem cell content. Cell 2010;140:62-73.

10 Li XJ, Ren ZJ, Tang JH, Yu Q: Exosomal MicroRNA MiR-1246 Promotes Cell Proliferation, Invasion and Drug Resistance by Targeting CCNG2 in Breast Cancer. Cell Physiol Biochem 2017;44:1741-1748.

11 Yang C, Tabatabaei SN, Ruan X, Hardy P: The Dual Regulatory Role of MiR-181a in Breast Cancer. Cell Physiol Biochem 2017;44:843-856.

-12 Bullock MD, Sayan AE, Packham GK, Mirnezami AH: MicroRNAs: critical regulators of epithelial to mesenchymal (EMT) and mesenchymal to epithelial transition (MET) in cancer progression. Biol Cell 2012;104:3-12.

-13 Lv ZD, Yang DX, Liu XP, Jin LY, Wang XG, Yang ZC, Liu D, Zhao JJ, Kong B, Li FN, Wang HB: MiR-212-5p Suppresses the Epithelial-Mesenchymal Transition in Triple-Negative Breast Cancer by Targeting Prrx2. Cell Physiol Biochem 2017;44:1785-1795.

14 Pan Y, Li C, Chen J, Zhang K, Chu X, Wang R, Chen L: The Emerging Roles of Long Noncoding RNA ROR (lincRNA-ROR) and its Possible Mechanisms in Human Cancers. Cell Physiol Biochem 2016;40:219-229.

15 Gwak JM, Kim HJ, Kim EJ, Chung YR, Yun S, Seo AN, Lee HJ, Park SY: MicroRNA-9 is associated with epithelial-mesenchymal transition, breast cancer stem cell phenotype, and tumor progression in breast cancer. Breast Cancer Res Treat 2014;147:39-49.

16 Roscigno G, Quintavalle C, Donnarumma E, Puoti I, Diaz-Lagares A, Iaboni M, Fiore D, Russo V, Todaro M, Romano G, Thomas R, Cortino G, Gaggianesi M, Esteller M, Croce CM, Condorelli G: MiR-221 promotes stemness of breast cancer cells by targeting DNMT3b. Oncotarget 2016;7:580-592. 


\section{Cellular Physiology Cell Physiol Biochem 2018;48:2205-2218

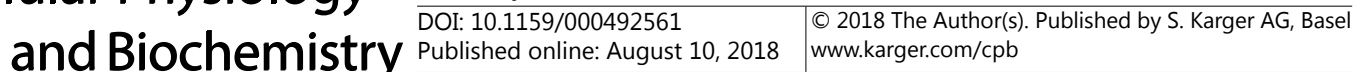

Cheng et al.: miRNA-9 and miRNA-221 as Key Regulators of Breast Cancer Stem Cell-like Cells

17 Patrawala L, Calhoun T, Schneider-Broussard R, Zhou J, Claypool K, Tang DG: Side population is enriched in tumorigenic, stem-like cancer cells, whereas ABCG2+ and ABCG2- cancer cells are similarly tumorigenic. Cancer Res 2005;65:6207-6219.

18 Cheng CW, Wang HW, Chang CW, Chu HW, Chen CY, Yu JC, Chao JI, Liu HF, Ding SL, Shen CY: MicroRNA-30a inhibits cell migration and invasion by downregulating vimentin expression and is a potential prognostic marker in breast cancer. Breast Cancer Res Treat 2012;134:1081-1093.

19 Elston CW, Ellis IO: Pathological prognostic factors in breast cancer. I. The value of histological grade in breast cancer: experience from a large study with long-term follow-up. Histopathology 1991:19:403-410.

-20 Singletary SE, Connolly JL: Breast cancer staging: working with the sixth edition of the AJCC Cancer Staging Manual. CA: Cancer J Clin 2006;56:37-47.

-21 Pfaffl MW: A new mathematical model for relative quantification in real-time RT-PCR. Nucleic Acid Res 2001;29:e45.

-22 Chu HW, Cheng CW, Chou WC, Hu LY, Wang HW, Hsiung CN, Hsu HM, Wu PE, Hou MF, Shen CY, Yu JC: A novel estrogen receptor-microRNA 190a-PAR-1-pathway regulates breast cancer progression, a finding initially suggested by genome-wide analysis of loci associated with lymph-node metastasis. Human Mol Genet 2014;23:355-367.

23 Sun S, Qiu XS: Cancer stem cells and tumor metastasis. J Cancer Research Ther 2013;9:S150-152.

24 Neth P, Ries C, Karow M, Egea V, Ilmer M, Jochum M: The Wnt signal transduction pathway in stem cells and cancer cells: influence on cellular invasion. Stem Cell Rev 2007;3:18-29.

$>25$ Chen J, Li Y, Yu TS, McKay RM, Burns DK, Kernie SG, Parada LF: A restricted cell population propagates glioblastoma growth after chemotherapy. Nature 2012;488:522-526.

26 Lee G, Hall RR 3rd, Ahmed AU: Cancer Stem Cells: Cellular Plasticity, Niche, and its Clinical Relevance. J Stem Cell Res Ther 2016;6:pii:363.

-27 Ding X, Park SI, McCauley LK, Wang CY: Signaling between transforming growth factor beta (TGF-beta) and transcription factor SNAI2 represses expression of microRNA miR-203 to promote epithelial-mesenchymal transition and tumor metastasis. J Biol Chem 2013;288:10241-10253.

28 Lu X, Ma J, Chu J, Shao Q, Zhang Y, Lu G, Li J, Huang X, Li W, Li Y, Ling Y, Zhao T: MiR-129-5p Sensitizes the Response of Her-2 Positive Breast Cancer to Trastuzumab by Reducing Rps6. Cell Physiol Biochem 2017;44:2346-2356.

29 Vetter G, Saumet A, Moes M, Vallar L, Le Bechec A, Laurini C, Sabbah M, Arar K, Theillet C, Lecellier CH, Friederich E: miR-661 expression in SNAI1-induced epithelial to mesenchymal transition contributes to breast cancer cell invasion by targeting Nectin-1 and StarD10 messengers. Oncogene 2010;29:4436-4448.

30 Callegari E, Elamin BK, Giannone F, Milazzo M, Altavilla G, Fornari F, Giacomelli L, D'Abundo L, Ferracin M, Bassi C, Zagatti B, Corrà F, Miotto E, Lupini L, Bolondi L, Gramantieri L, Croce CM, Sabbioni S, Negrini M: Liver tumorigenicity promoted by microRNA-221 in a mouse transgenic model. Hepatology 2012;56:10251033.

-31 Tanaka R, Tomosugi M, Horinaka M, Sowa Y, Sakai T: Metformin Causes G1-Phase Arrest via DownRegulation of MiR-221 and Enhances TRAIL Sensitivity through DR5 Up-Regulation in Pancreatic Cancer Cells. PloS One 2015;10:e0125779.

-32 White RA, Neiman JM, Reddi A, Han G, Birlea S, Mitra D, Dionne L, Fernandez P, Murao K, Bian L, Keysar SB, Goldstein NB, Song N, Bornstein S, Han Z, Lu X, Wisell J, Li F, Song J, Lu SL, Jimeno A, Roop DR, Wang $\mathrm{XJ}$ : Epithelial stem cell mutations that promote squamous cell carcinoma metastasis. J Clin Invest 2013;123:4390-4404.

33 Liu M, Zhu H, Yang S, Wang Z, Bai J, Xu N: c-Myc suppressed E-cadherin through miR-9 at the posttranscriptional level. Cell Biology Int 2013;37:197-202.

34 Ma L, Young J, Prabhala H, Pan E, Mestdagh P, Muth D, Teruya-Feldstein J, Reinhardt F, Onder TT, Valastyan S, Westermann F, Speleman F, Vandesompele J, Weinberg RA: miR-9, a MYC/MYCN-activated microRNA, regulates E-cadherin and cancer metastasis. Nat Cell Biol 2010;12:247-256.

35 Munoz JL, Rodriguez-Cruz V, Rameshwar P: High expression of miR-9 in CD133+ glioblastoma cells in chemoresistance to temozolomide. J Cancer Stem Cell Res 2015, 3.

-36 Munoz JL, Bliss SA, Greco SJ, Ramkissoon SH, Ligon KL, Rameshwar P: Delivery of Functional Anti-miR-9 by Mesenchymal Stem Cell-derived Exosomes to Glioblastoma Multiforme Cells Conferred Chemosensitivity. Mol Ther Nucleic Acids 2013:2:e126. 


\section{Cellular Physiology Cell Physiol Biochem 2018;48:2205-2218 \begin{tabular}{l|l} 
DOI: 10.1159/000492561 & Ond Biochemistry \\
Published online: August 10, 2018 & $\begin{array}{l}\text { 2018 The Author(s). Published by S. Karger AG, Basel } \\
\text { www.karger.com/cpb }\end{array}$ \\
\cline { 2 - 3 }
\end{tabular} \\ Cheng et al.: miRNA-9 and miRNA-221 as Key Regulators of Breast Cancer Stem Cell-like Cells}

-37 Li B, Lu Y, Wang H, Han X, Mao J, Li J, Yu L, Wang B, Fan S, Yu X, Song B: miR-221/222 enhance the tumorigenicity of human breast cancer stem cells via modulation of PTEN/Akt pathway. Biomed Pharmacother 2016;79:93-101.

-38 Stinson S, Lackner MR, Adai AT, Yu N, Kim HJ, O'Brien C, Spoerke J, Jhunjhunwala S, Boyd Z, Januario T, Newman RJ, Yue P, Bourgon R, Modrusan Z, Stern HM, Warming S, de Sauvage FJ, Amler L, Yeh RF, Dornan D: miR-221/222 targeting of trichorhinophalangeal 1 (TRPS1) promotes epithelial-to-mesenchymal transition in breast cancer. Sci Signal 2011;4:pt5.

39 Zheng L, Qi T, Yang D, Qi M, Li D, Xiang X, Huang K, Tong Q: microRNA-9 suppresses the proliferation, invasion and metastasis of gastric cancer cells through targeting cyclin D1 and Ets1. PloS One 2013;8:e55719.

40 Lu J, Luo H, Liu X, Peng Y, Zhang B, Wang L, Xu X, Peng X, Li G, Tian W, He ML, Kung H, Li XP: miR-9 targets CXCR4 and functions as a potential tumor suppressor in nasopharyngeal carcinoma. Carcinogenesis 2014;35:554-563.

41 Liu S, Kumar SM, Lu H, Liu A, Yang R, Pushparajan A, Guo W, Xu X: MicroRNA-9 up-regulates E-cadherin through inhibition of NF-kappaB1-Snail1 pathway in melanoma. J Pathol 2012;226:61-72.

42 Gyorffy B, Benke Z, Lanczky A, Balazs B, Szallasi Z, Timar J, Schafer R: RecurrenceOnline: an online analysis tool to determine breast cancer recurrence and hormone receptor status using microarray data. Breast Cancer Res Treat 2012;132:1025-1034.

-43 Song N, Choi JY, Sung H, Jeon S, Chung S, Park SK, Han W, Lee JW, Kim MK, Lee JY, Yoo KY, Han BG, Ahn SH, Noh DY, Kang D: Prediction of breast cancer survival using clinical and genetic markers by tumor subtypes. PLoS One 2015;10:e0122413.

44 Shimono Y, Zabala M, Cho RW, Lobo N, Dalerba P, Qian D, Diehn M, Liu H, Panula SP, Chiao E, Dirbas FM, Somlo G, Pera RA, Lao K, Clarke MF: Downregulation of miRNA-200c links breast cancer stem cells with normal stem cells. Cell 2009;138:592-603.

45 Galardi S, Mercatelli N, Giorda E, Massalini S, Frajese GV, Ciafre SA, Farace MG: miR-221 and miR-222 expression affects the proliferation potential of human prostate carcinoma cell lines by targeting p27Kip1. J Biol Chem 2007;282:23716-23724.

-46 Liu Z, Wang C, Jiao X, Zhao S, Liu X, Wang Y, Zhang J: miR-221 promotes growth and invasion of hepatocellular carcinoma cells by constitutive activation of NFkappaB. Am J Transl Res 2016;8:4764-4777.

47 Minor J, Wang X, Zhang F, Song J, Jimeno A, Wang XJ, Lu X, Gross N, Kulesz-Martin M, Wang D, Lu SL: Methylation of microRNA- 9 is a specific and sensitive biomarker for oral and oropharyngeal squamous cell carcinomas. Oral oncology 2012;48:73-78.

48 Song Y, Li J, Zhu Y, Dai Y, Zeng T, Liu L, Li J, Wang H, Qin Y, Zeng M, Guan XY, Li Y: MicroRNA-9 promotes tumor metastasis via repressing E-cadherin in esophageal squamous cell carcinoma. Oncotarget 2014;5:11669-11680.

-49 Sondermann A, Andreghetto FM, Moulatlet AC, da Silva Victor E, de Castro MG, Nunes FD, Brandao LG, Severino P: MiR-9 and miR-21 as prognostic biomarkers for recurrence in papillary thyroid cancer. Clin Exp Metastasis 2015;32:521-530. 